\title{
Article \\ Fault Diagnosis Using Cascaded Adaptive Second-Order Tristable Stochastic Resonance and Empirical Mode Decomposition
}

\author{
Hongjiang Cui ${ }^{1}$, Ying Guan ${ }^{1, *}$ and Wu Deng ${ }^{2,3, *}$ \\ 1 School of Locomotive and Rolling Stock Engineering, Dalian Jiaotong University, Dalian 116028, China; \\ chj@djtu.edu.cn \\ 2 School of information and Engineering, Sichuan Tourism University, Chengdu 610100, China \\ 3 School of Electronic Information and Automation, Civil Aviation University of China, Tianjin 300300, China \\ * Correspondence: guanying2017@djtu.edu.cn (Y.G.); wdeng@cauc.edu.cn (W.D.)
}

check for updates

Citation: Cui, H.; Guan, Y.; Deng, W. Fault Diagnosis Using Cascaded Adaptive Second-Order Tristable Stochastic Resonance and Empirical Mode Decomposition. Appl. Sci. 2021, 11, 11480. https://doi.org/10.3390/ app112311480

Academic Editor: Jordi Cusido

Received: 27 October 2021

Accepted: 30 November 2021

Published: 3 December 2021

Publisher's Note: MDPI stays neutral with regard to jurisdictional claims in published maps and institutional affiliations.

Copyright: (C) 2021 by the authors. Licensee MDPI, Basel, Switzerland. This article is an open access article distributed under the terms and conditions of the Creative Commons Attribution (CC BY) license (https:/ / creativecommons.org/licenses/by/ $4.0 /)$.

\begin{abstract}
Aiming at the problems of poor decomposition quality and the extraction effect of a weak signal with strong noise by empirical mode decomposition (EMD), a novel fault diagnosis method based on cascaded adaptive second-order tristable stochastic resonance (CASTSR) and EMD is proposed in this paper. In the proposed method, low-frequency interference components are filtered by using high-pass filtering, and the restriction conditions of stochastic resonance theory are solved by using an ordinary variable-scale method. Then, a chaotic ant colony optimization algorithm with a global optimization ability is employed to adaptively adjust the parameters of the second-order tristable stochastic resonance system to obtain the optimal stochastic resonance, and noise reduction pretreatment technology based on CASTSR is developed to enhance the weak signal characteristics of low frequency. Next, the EMD is employed to decompose the denoising signal and extract the characteristic frequency from the intrinsic mode function (IMF), so as to realize the fault diagnosis of rolling bearings. Finally, the numerical simulation signal and actual bearing fault data are selected to prove the validity of the proposed method. The experiment results indicate that the proposed fault diagnosis method can enhance the decomposition quality of the EMD, effectively extract features of weak signals, and improve the accuracy of fault diagnosis. Therefore, the proposed fault diagnosis method is an effective fault diagnosis method for rotating machinery.
\end{abstract}

Keywords: fault diagnosis; cascaded adaptive stochastic resonance; empirical mode decomposition; second-order tristable state; chaotic ant colony optimization; feature extraction

\section{Introduction}

As a basic part of mechanical equipment, rolling bearing is often one of the fuses of equipment failure [1-3]. As most of the mechanical equipment in industrial production is in a very noisy environment, it is difficult to find the early weak failure, and, even when the mechanical equipment has a more serious failure caused by the early weak failure, it is still impossible to judge the problem manually [4-6]. Therefore, the main purpose of the study is to extract the weak signal characteristics of mechanical equipment under strong noise so as to implement weak fault diagnosis.

Empirical mode decomposition (EMD) is a widely used time-frequency analysis method, which is extremely suitable for analyzing nonlinear and nonstationary signals because it stabilizes the signal by decomposing [7]. Zhang et al. [8] used variational mode decomposition for fault diagnosis of the rolling bearings. Hong et al. [9] used wavelet packet to modulate bearing signals, and then EMD was used to extract fault features. Guo et al. [10] combined EMD with fast Fourier transform (FFT). In this method, the useless high-frequency noise components and useful high signal-to-noise ratio (SNR) components were decomposed by using EMD, and fast Fourier transform was performed on useful components. 
At present, most of the weak signal features are extracted through noise suppression, which is effective but also has problems: it inhibits both noise and target features at the same time. When the noise intensity is low, it may have little effect; however, when the noise intensity is high, the weak fault features may become more difficult to extract. The theoretical basis of stochastic resonance is quite different from traditional noise suppression methods. It transfers the noise energy to the low-frequency region with weak features and strengthens the weak signal features by weakening and transferring noise. Therefore, it is of great significance for weak signal feature extraction under strong noise. Variational mode decomposition (VMD) and analytical mode decomposition are used to extract features of multi-steady stochastic resonance. Wang [11] studied the structure of multi-steady signalnoise ratio(SNR) and influence of parameters, and the average output SNR was taken as the objective function of the multi-steady stochastic resonance output. The composite fault signals were used for simulation verification. Han [12] made use of the advantages of multi-steady state and wavelet transform to realize the bearing fault detection. $\mathrm{Li}$ et al. [13] developed a new fault feature extraction method for bearing prognostics. Two real bearing run-to-failure test datasets are used to demonstrate the effectiveness. Zhu et al. [14] proposed a fault feature extraction method for bearings to realize bearing fault diagnosis. Chen et al. [15] proposed a multi-scale alternating direction multiplier method in order to extract a fault impact signal. In addition, some signal feature extraction methods have been proposed in recent years [8,16-26].

EMD has been recognized by scholars and further studies since it was proposed [27]. It has been widely used in the field of fault diagnosis of rolling bearings and has shown many advantages and conveniences, but it also has some disadvantages. In order to overcome its disadvantages, a chaotic ant colony optimization algorithm with global optimization capability is introduced to adaptively adjust the parameters of the second-order tristable stochastic resonance system to obtain optimal stochastic resonance, and a fault diagnosis method based on CASTSR and EMD is proposed in this paper. In the proposed method, the interference components of low frequency are filtered by high-pass filtering, the limitation of stochastic resonance theory is solved by using an ordinary variable-scale method, and a high-frequency signal is transformed into a low-frequency signal far lower than $1 \mathrm{~Hz}$. Each CASTSR output SNR is taken as the objective function, the chaotic ant colony algorithm is used to calculate the optimal parameter combination when the output SNR of each stage is maximum, and the optimal results of each stage are input into the stochastic resonance system to achieve a sufficient noise reduction of weak signals. After that, EMD is used for decomposition, and the characteristic frequency is extracted from the IMF for fault diagnosis.

The innovations and main contributions are described as follows:

- A novel fault diagnosis method based on CASTSR and EMD is proposed.

- The restriction conditions of stochastic resonance theory are solved by using an ordinary variable-scale method.

- The chaotic ACO with a global optimization ability is used to adaptively adjust the parameters of the CASTSR system to obtain the optimal stochastic resonance.

- The noise reduction pre-treatment technology based on CASTSR is realized to enhance the weak signal characteristics of low frequency.

- EMD is employed to decompose the denoising signal and extract the characteristic frequency from the IMF so as to realize fault diagnosis.

\section{Materials and Methods}

\subsection{Stochastic Resonance Model and Second-Order System}

The three-stable situation function model proposed by Wang [7] is adopted, and its potential function is expressed as follows:

$$
\begin{gathered}
=U_{v}(x)+U_{w s}(x) \\
=-\frac{a}{2} x^{2}+\frac{b}{4} x^{4}-\frac{V}{1+\exp \left(\frac{|x|-r}{c}\right)}
\end{gathered}
$$


The second-order stochastic resonance system can be described as follows:

$$
\frac{\mathrm{d}^{2} x}{\mathrm{~d} t^{2}}=-\frac{\mathrm{d} U(x)}{\mathrm{d} x}-k \frac{\mathrm{d} x}{\mathrm{~d} t}+s(t)+n(t)
$$

In the equation, $x$ is the output signal, $S(t)+n(t)$ is the input signal, $k$ is the damping factor, and $U(x)$ is the potential function. $n(t)=\sqrt{2 D} w(t), D$ is the noise intensity, and $w(t)$ is the Gaussian white noise. Substitute Equation (1) with Equation (2) to obtain the following:

$$
\begin{gathered}
\frac{\mathrm{d}^{2} x}{\mathrm{~d} t^{2}}=a x-b x^{3}-\frac{V}{c} \operatorname{sgn}(x) \exp \left(\frac{|x|-r}{c}\right)\left(1+\exp \left(\frac{|x|-r}{c}\right)\right)^{-2} \\
-k \frac{\mathrm{d} x}{\mathrm{~d} t}+s(t)+n(t) \\
\operatorname{sgn}= \begin{cases}1 & x>0 \\
0 & x=0 \\
-1 & x<0\end{cases}
\end{gathered}
$$

where Equation (3) is the functional expression of STSR; for the solution of STSR, Equation (3) is split into two first-order differential equations, and the parameter $y$ is introduced. If $\mathrm{d} x / \mathrm{d} t=y$, then the following equation is obtained:

$$
\left\{\begin{array}{c}
\frac{\mathrm{d} x}{\mathrm{~d} t}=y \\
\frac{\mathrm{d} y}{\mathrm{~d} t}=a x-b x^{3}-\frac{V}{c} \operatorname{sgn}(x) \exp \left(\frac{|x|-r}{c}\right) \\
\left(1+\exp \left(\frac{|x|-r}{c}\right)\right)^{-2}-k y+s(t)+n(t)
\end{array}\right.
$$

where Equations (3) and (5) are equivalent, the fourth-order Runge-Kutta algorithm is used to solve the Equation (3), which is described as follows:

$$
\left\{\begin{array}{l}
k_{1}=y_{n} \\
l_{1}=S_{n}-k k_{1}-U^{\prime}\left(x_{n}\right) \\
k_{2}=y_{n}+0.5 h l_{1} \\
l_{2}=S_{n}-k k_{2}-U^{\prime}\left(x_{n}+0.5 h k_{1}\right) \\
k_{3}=y_{n}+0.5 h l_{2} \\
l_{3}=S_{n+1}-k k_{3}-U^{\prime}\left(x_{n}+0.5 h k_{2}\right) \\
k_{4}=y_{n}+h l_{3} \\
l_{4}=S_{n+1}-k k_{4}-U^{\prime}\left(x_{n}+h k_{3}\right) \\
x_{n+1}=x_{n}+(h / 6)\left(k_{1}+2 k_{2}+2 k_{3}+k_{4}\right) \\
y_{n+1}=y_{n}+(h / 6)\left(l_{1}+2 l_{2}+2 l_{3}+l_{4}\right)
\end{array}\right.
$$

where $S_{n}$ is the input signal of stochastic resonance, $x_{n}$ is the output signal of stochastic resonance, and $h$ is the step size of numerical calculation.

\subsection{Chaotic Ant Colony Optimization Algorithm}

A chaotic ant colony optimization (CACO) algorithm is a combination of chaos search and the ant colony optimization algorithm. After the ant colony search is completed, chaos is used to improve the search accuracy and avoid falling into the local optimum [28-40]. Therefore, the CACO algorithm takes on a global optimization ability. In addition, some new optimization algorithms have been proposed in recent years [41-55].

Pheromones are substances secreted by an individual outside the body and detected by other individuals of the same species through olfactory organs, so that the latter shows some changes in behavior, emotion, psychological, or physiological mechanisms [56-58]. Since the selection of stochastic resonance system parameters plays an important role 
and the ACO has the same pheromone on each path during initialization, the pheromone update formula can be expressed as follows:

$$
\tau_{i j}(t+1)=(1-\rho) \tau_{i j}(t)+\Delta \tau_{i j}(t)
$$

where $\tau_{i j}(t)$ represents the pheromone quantity on branch $j$ at time $t$. When $t=0$, the information intensity on each path is equal, and $\rho$ represents the volatile factor of the global pheromone, generally valued as $[0,1]$, which determines the volatilization speed of the pheromone. When each ant is looking for a path, has the same probability, and the searching period is long, the CACO is used to optimize the parameters of the stochastic resonance system, and the ergodicity of the chaos algorithm is introduced to initialize chaos. The iteration formula is described as follows:

$$
Z_{i j}(t+1)=\mu Z_{l j}(t)\left[1-Z_{i j}(t)\right]
$$

where $\mu$ is the control parameter, and its value is [3.56,4]. When $\mu=4,0 \leq Z_{i j} \leq 1$, logistics mapping is completely chaotic. In order to avoid local optimization problems in the process of ACO, chaos disturbance was added to the process of pheromone adjustment so as to realize the whole optimization [59-61]. The pheromone adjustment of the CACO algorithm is described as follows:

$$
\tau_{i j}(t+1)=(1-\rho) \tau_{i j}(t)+\Delta \tau_{i j}(t)+q_{1} Z_{i j}(t)
$$

where $Z_{i j}(t)$ is a chaotic variable, which is obtained by iteration of Equation (8), and $q_{1}$ is a coefficient.

The specific steps of the chaotic ACO are described as follows.

- Step 1. Set the initial parameter and the maximum iteration Ncmax and generate a group of chaotic variables corresponding to the parameters to make the pheromone chaos.

- Step 2. Establish the solution space, put in a random ant, and establish the tabu table (Tabuk). The ant is now walking on a collection of points, and the initial point creates the allowed table, that is, the accessible points.

- Step 3. Each ant randomly selects the next point to visit; record each point in Tabuk. Update the pheromone and continue the process until all points within the set parameter range are recorded in Tabuk.

- Step 4. After all the ants have walked each point for the first time, record the current best result.

- In order to avoid local optimization of the parameters, use Equation (9) to update the pheromones.

- Step 5. When a number of iterations is completed, the algorithm stops. Otherwise, clear Tabuk and go to step 3 to recalculate. When there is no better result after several iterations, stop the algorithm and output the optimal value.

\subsection{Adaptive Second-Order Tristable Stochastic Resonance Method Based on CACO}

The parameter selection of the stochastic resonance method determines its ability to enhance weak signal characteristics. Therefore, the chaotic ACO with global optimization performance was introduced to optimize the parameters of STSR in order to obtain the best stochastic resonance method. That is, the objective function of optimization parameters for CACO is set as the output SNR, which can reflect the advantages and disadvantages of the system output. The parameters $a, b, V, r$, and $c$ of the STSR system were adjusted adaptively by using the CACO algorithm, and the optimal STSR method was obtained. The flow of adaptive STSR method is shown in Figure 1.

The process of the adaptive STSR method based on the CACO algorithm is described as follows:

- Step 1. Signal preprocessing. For the simulation data, the simulation signal is first passed through a high-pass filter, and then the variable-scale processing is carried out. 
This processing ensures that the signal is input into the stochastic resonance system in order to meet the condition that the frequency signal is less than $1 \mathrm{~Hz}$. As for the bearing vibration signal, it needs to be transformed into an envelope signal before the signal is processed.

- $\quad$ Step 2. The parameters $a, b, V, r$ and $c$ are optimized by using the CACO algorithm.

- Step 3. The optimal parameters are input into the stochastic resonance system to extract fault features, and then the fault diagnosis is completed.

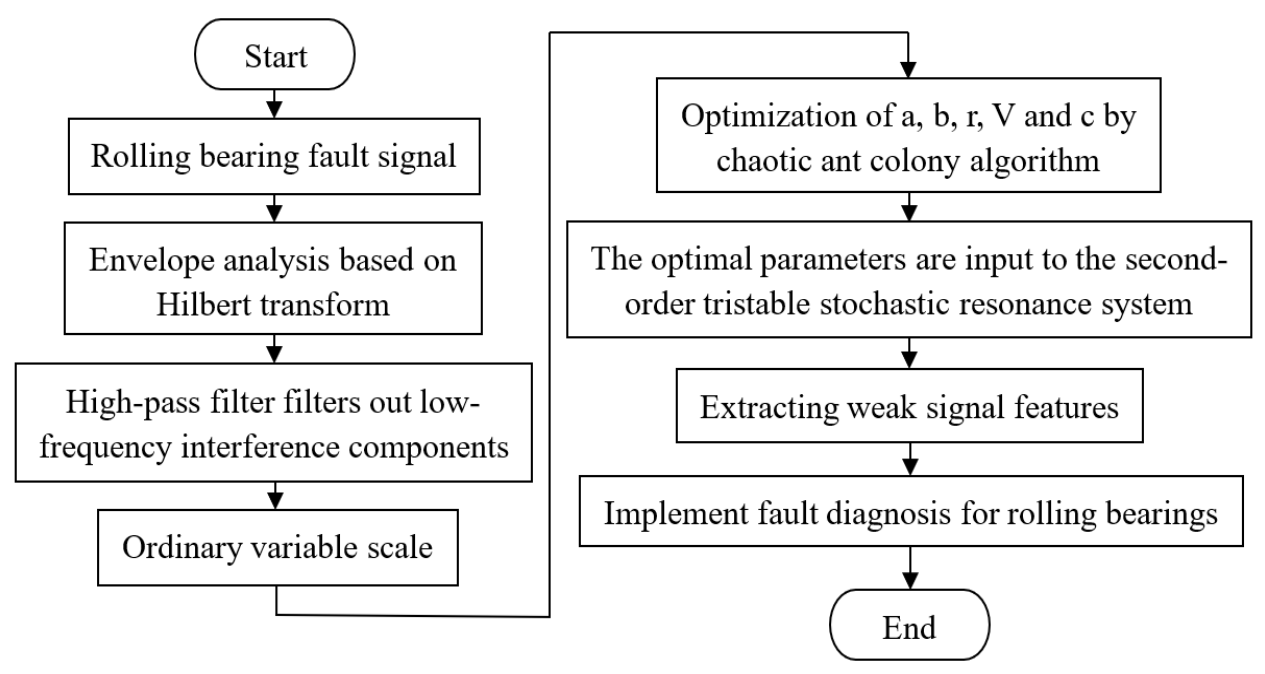

Figure 1. The flow of adaptive STSR method.

\subsection{Cascaded Adaptive Second-Order Tristable Stochastic Resonance}

Several single-stage adaptive second-order tristable stochastic resonances are connected in a series to form the cascaded adaptive second-order tristable stochastic resonances (CASTSR). Its structure block is shown in Figure 2.

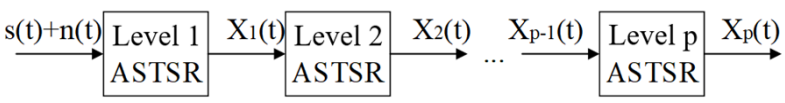

Figure 2. Block of CASTSR system.

Where, $s(t)$ and $n(t)$ represent input signal and noise of CASTSR, respectively. $p$ represents the series of CASTSR, $X_{p}$ represents the output signal of CASTSR at level $p$ and the input signal of CASTSR at the next level.

\subsection{Fault Diagnosis Based on CASTSR}

Accurate fault feature extraction is the key to fault diagnosis. As most fault signals collected in practical engineering are in strong noise, their characteristic signals are weak and polluted by the strong noise. Their signal-to-noise ratio is extremely low, and they cannot be identified directly. Therefore, the cascaded adaptive second-order tristable stochastic resonance method (CASTSR) is used to extract the features of weak signals to realize the fault diagnosis of rolling bearings. The CASTSR method uses the principle of stochastic resonance to continuously transfer noise energy in the signal to be measured from the high-frequency region to the low-frequency region. Thus, the weak signal characteristics of the low-frequency region need to be enhanced. The output SNR of the adaptive secondorder tristable stochastic resonance method for each stage was taken as the objective function, and the optimal parameter combination for the maximum output SNR of each stage was calculated by using the $u$ algorithm. The optimal results of each stage were obtained by inputting the SNR of each stage into the stochastic resonance system. 
The detailed fault diagnosis process based on CASTSR for rolling bearings is shown in Figure 3.
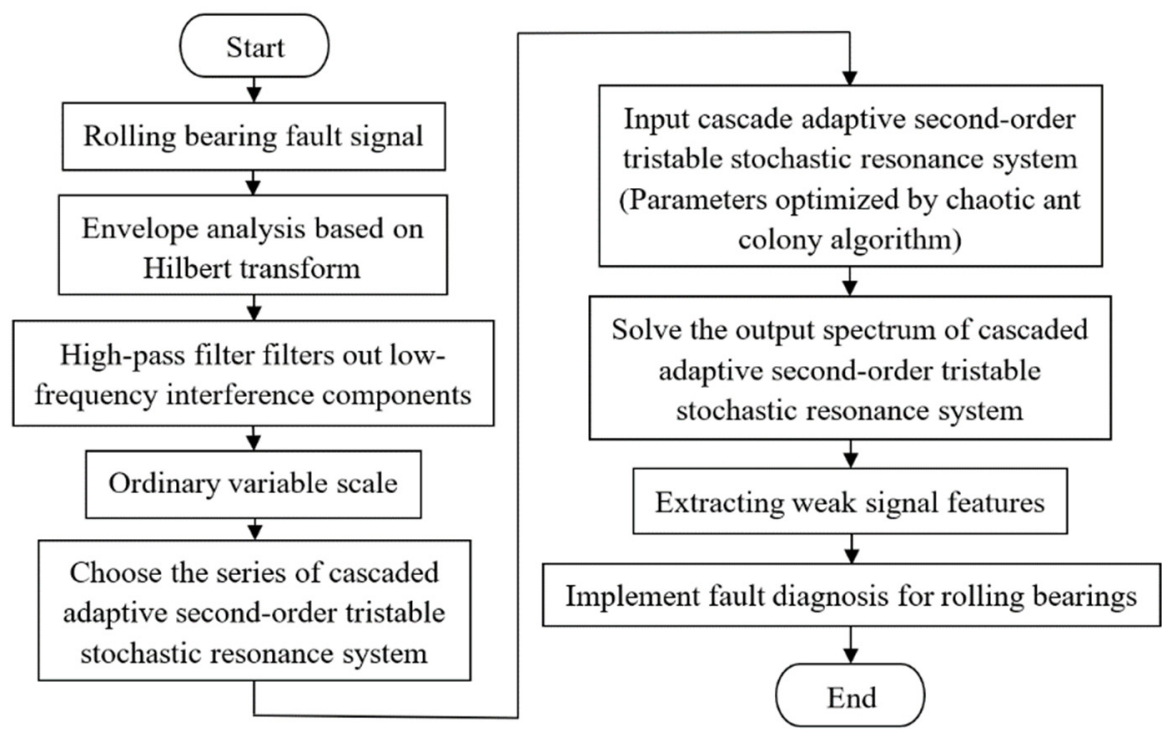

Figure 3. The detailed fault diagnosis process based on CASTSR for rolling bearings.

\section{Fault Diagnosis Method Based on CASTSR and EMD}

To solve the mode-aliasing problem of EMD decomposition, improve the accuracy of EMD decomposition and make the extracted characteristic frequency more prominent, it is essential to carry out pre-noise reduction before the signal is measured. Therefore, a cascade system needs to select the appropriate series so that the characteristic frequency obtained by EMD decomposition of the signal after denoising is in IMF1. For this purpose, Hilbert transform is adopted to propose a rolling bearing fault diagnosis method based on CASTSR and EMD. The specific steps of the proposed fault diagnosis method are described as follows:

- Step 1. The signal was transformed into an envelope signal by Hilbert transformation, which is passed into a high-pass filter to filter interference components in the lowfrequency region. The simulation signal is directly passed into the high-pass filter.

- Step 2. The filtered signal is input into the CASTSR system for noise reduction pretreatment. Then, EMD is used to process output results of the first-stage stochastic resonance system. If the characteristic frequency is in IMF1, stop this method.

- Step 3. If the characteristic frequency is not in IMF1, EMD is used to process the results of the stochastic resonance system at the next level until the characteristic frequency is in IMF1.

- Step 4. According to the extracted characteristic frequency, the fault diagnosis of rolling bearing is carried out.

The fault diagnosis flow based on CASTSR and EMD is shown in Figure 4. 


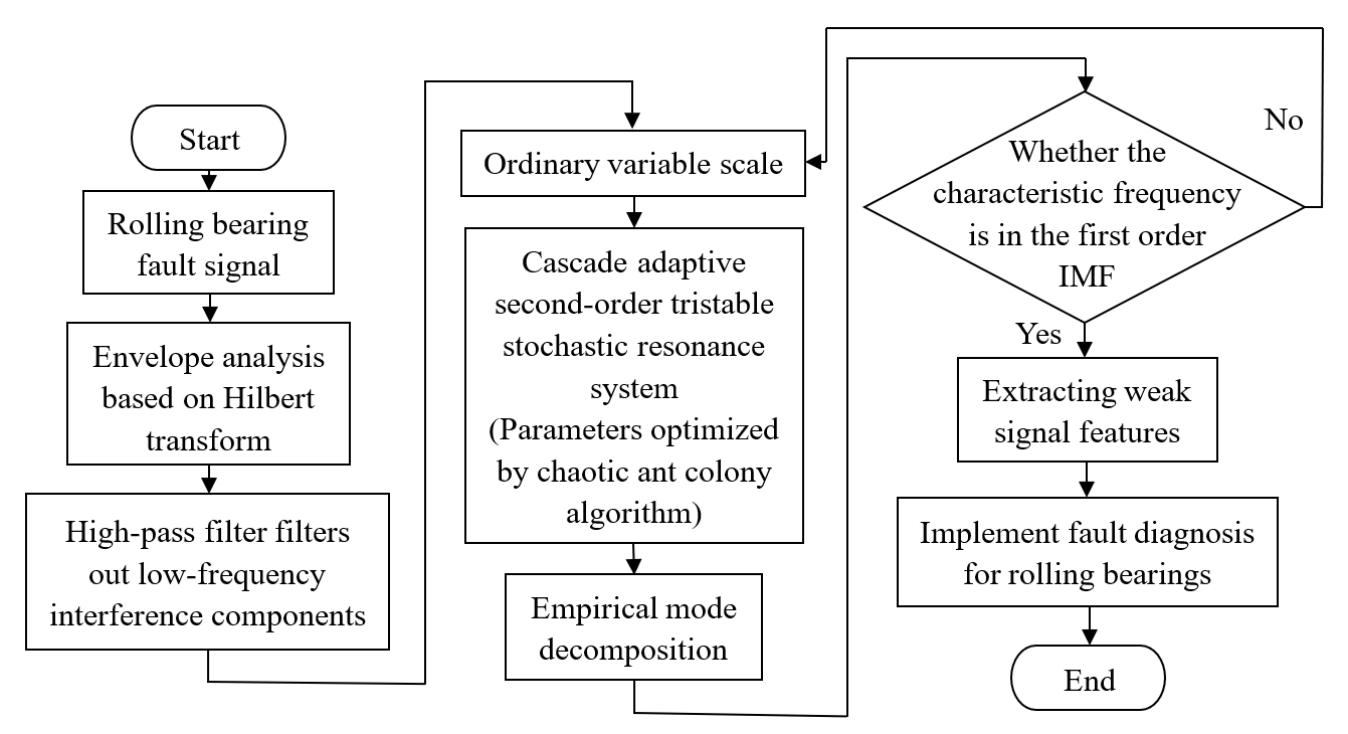

Figure 4. Fault diagnosis flow based on CASTSR and EMD.

\section{Simulation Experiment and Analysis}

A simulation noisy signal with $50 \mathrm{~Hz}$ is used to prove the effectiveness of the proposed method. The simulation signal is $S(t)=0.1 \sin (2 \times \pi \times 50 \times t)+n(t)$, and $n(t)$ is Gaussian white noise with an intensity of 0.5 . The sampling frequency of the signal is $3 \mathrm{kHz}$, and the sampling number is 3000. Its frequency domain waveform is shown in Figure 5. Due to too much interference noise, it is impossible to extract the fault characteristics. The SNR is $-27.58 \mathrm{Db}$ by calculation, which indicates that the characteristic frequency is heavily polluted by noise. The original signal is passed into the high-pass filter, and the frequency domain waveform is shown in Figure 6. The CASTSR is used to extract the features of weak signals. The output spectrum of the first-order adaptive second-order tristable system and second-order adaptive second-order tristable system is shown in Figures 7 and 8.

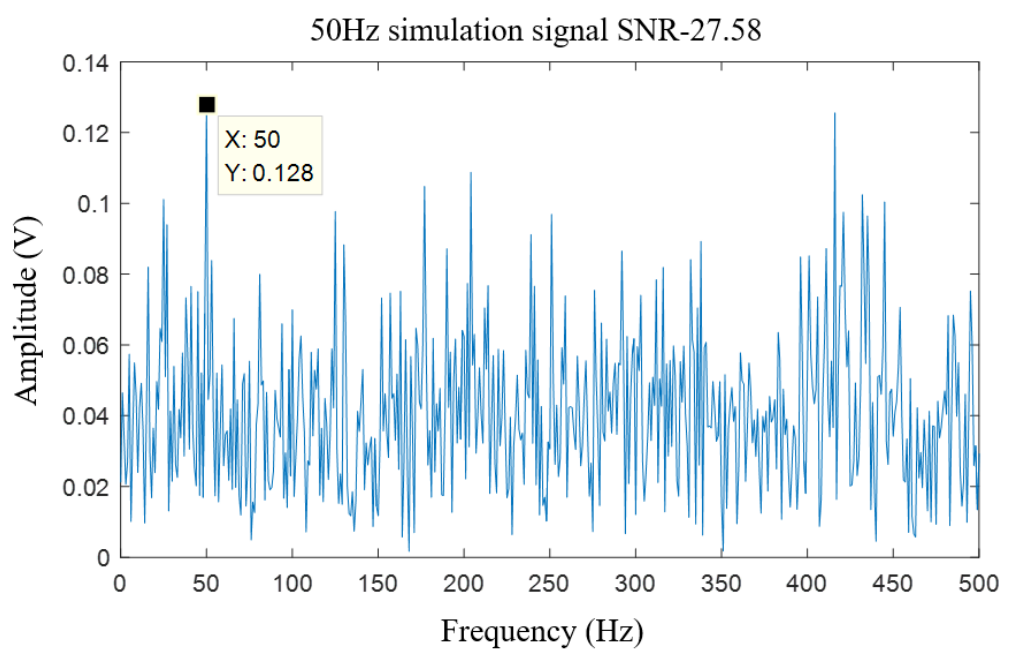

Figure 5. The frequency domain waveform of the original signal.

As can be seen from Figure 7, after the input signal goes through the first-order stochastic resonance, noise energy is transferred from the high frequency to the low frequency. As a result, the high-frequency noise is weakened, while the fault feature of the low frequency is strengthened. However, there is still a little noise around the characteristic frequency of $50 \mathrm{~Hz}$, and the characteristic frequency is extracted, but it is weak. As can be seen from Figure 8, after the second stage of stochastic resonance is carried out, noise energy is transferred from the high frequency to the low frequency, and the fault characteristics of the 
low frequency are strengthened further by resonance. At this point, there is still some noise interference around the characteristic frequency, and the peak value at the characteristic frequency begins to stand out. Compared with the noise-interference components in the cascaded stochastic resonance output of the first stage, the noise-interference components in the second stage are greatly reduced, and the characteristic frequency can be effectively identified. As can be seen from the frequency domain waveform in Figures 5 and 6, the peak values of the input signal, the results of the first stage stochastic resonance, and the results of the second stage stochastic resonance are all superior to those of the upper stage at the characteristic frequency of $50 \mathrm{~Hz}$. In addition, from the viewpoint of the calculated output SNR, the first-stage SNR reaches $-17.53 \mathrm{~dB}$, which is $10.05 \mathrm{~dB}$ higher than the input signal. The SNR of the second stage reached $-17.12 \mathrm{~dB}$, which is $0.41 \mathrm{~dB}$ higher than that of the first stage. In general, the effect of stochastic resonance is significant, which verifies the effectiveness of the CASTSR method to further extract weak signal features.

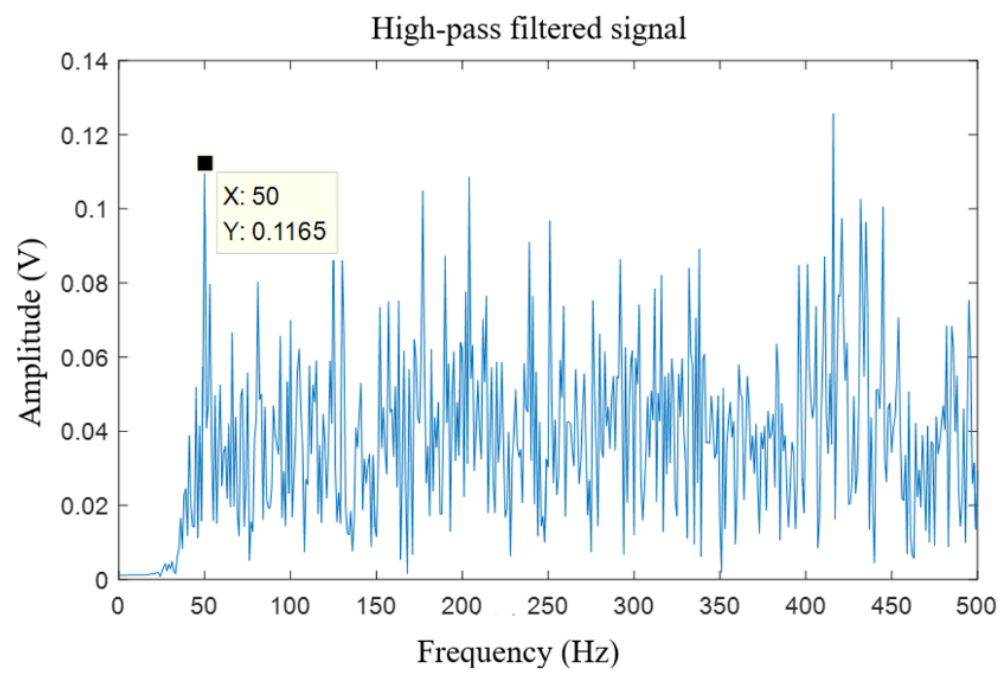

Figure 6. The frequency domain waveform of the high-pass filtered signal.

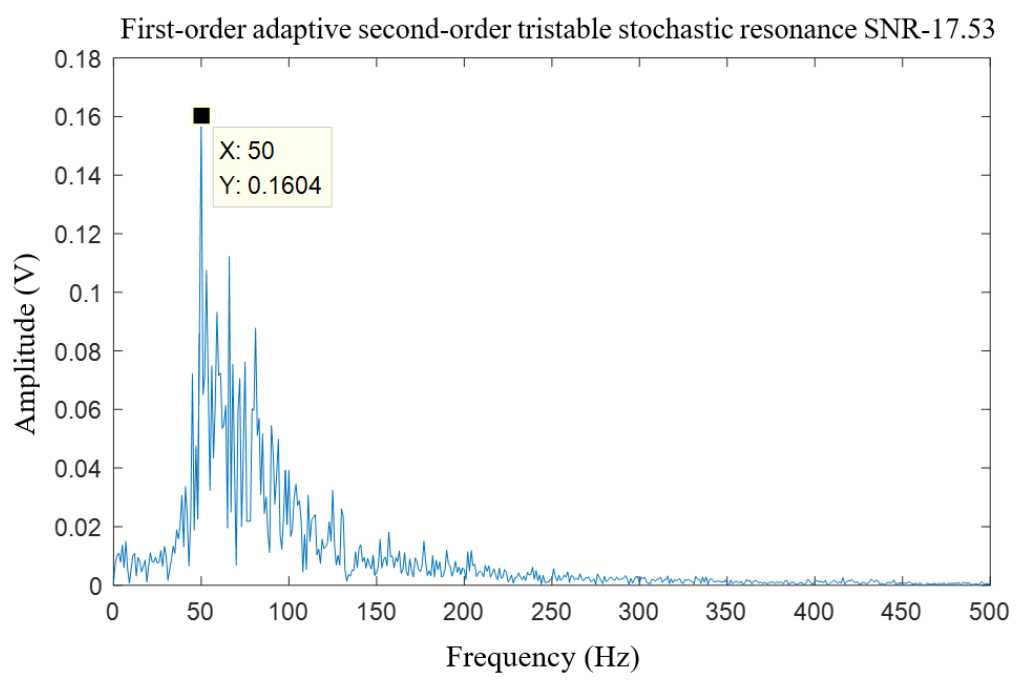

Figure 7. The output spectrum of the first cascade system. 
Second stage adaptive second-order tristable stochastic resonance SNR-17.12

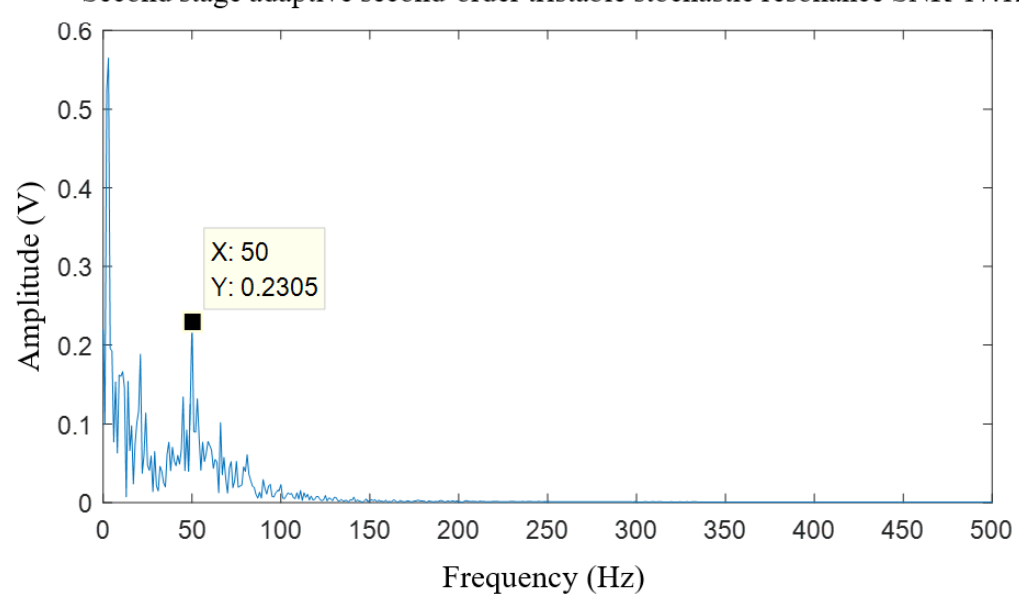

Figure 8. The output spectrum of the second cascade system.

The processing results of the original noisy signals by EMD are shown in Figure 9.

EMD spectrum of $50 \mathrm{~Hz}$ simulation signal
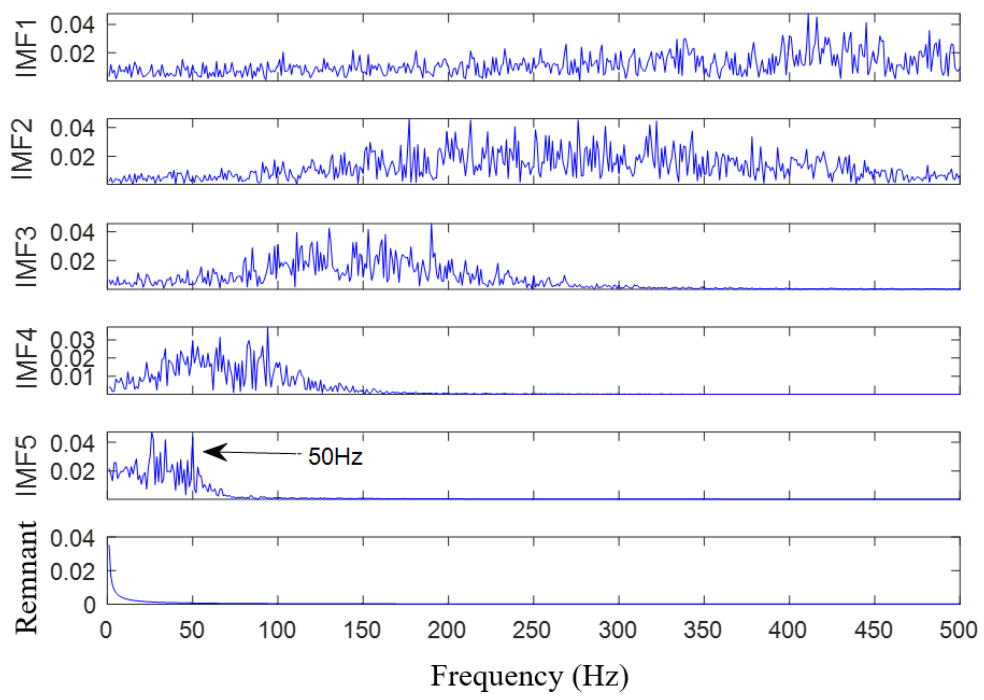

Figure 9. The processing results of the original noisy signals.

As can be seen from Figure 9, the decomposition results of the original signal show that the first four orders are high-frequency noise-containing components, and the characteristic frequency of $50 \mathrm{~Hz}$ appears in IMF5, but there is a lot of interference noise around it, so fault features cannot be accurately extracted. The proposed CASTSR was used to extract the weak signal features.

The proposed CASTSR was used to extract the weak signal features. The processing results of the first-order stochastic resonance output are shown in Figure 10. The processing results of the second-order stochastic resonance output are shown in Figure 11.

In Figure 10, IMF1 is a high-frequency interference component, in which the characteristic frequency is submerged. The characteristic frequency appears in IMF2, where the surrounding noise is less, and the characteristic frequency can be clearly identified. Compared with the result without denoising, the IMF order of EMD decomposition decreases by two orders after denoising. According to the processing results of the second-order stochastic resonance output in Figure 11, it can be seen that the characteristic frequency appears in IMF1. Compared with the first-order result, the ambient noise is effectively 
transferred to the characteristic frequency, and the IMF order of EMD decomposition is reduced by one order.

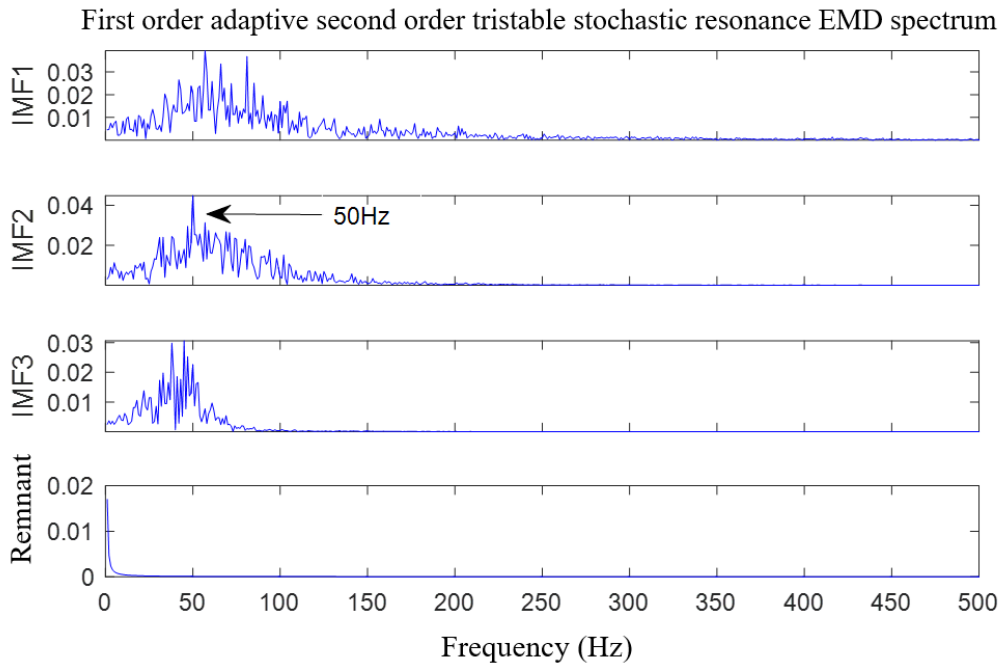

Figure 10. The processing results of the first-order stochastic resonance output.
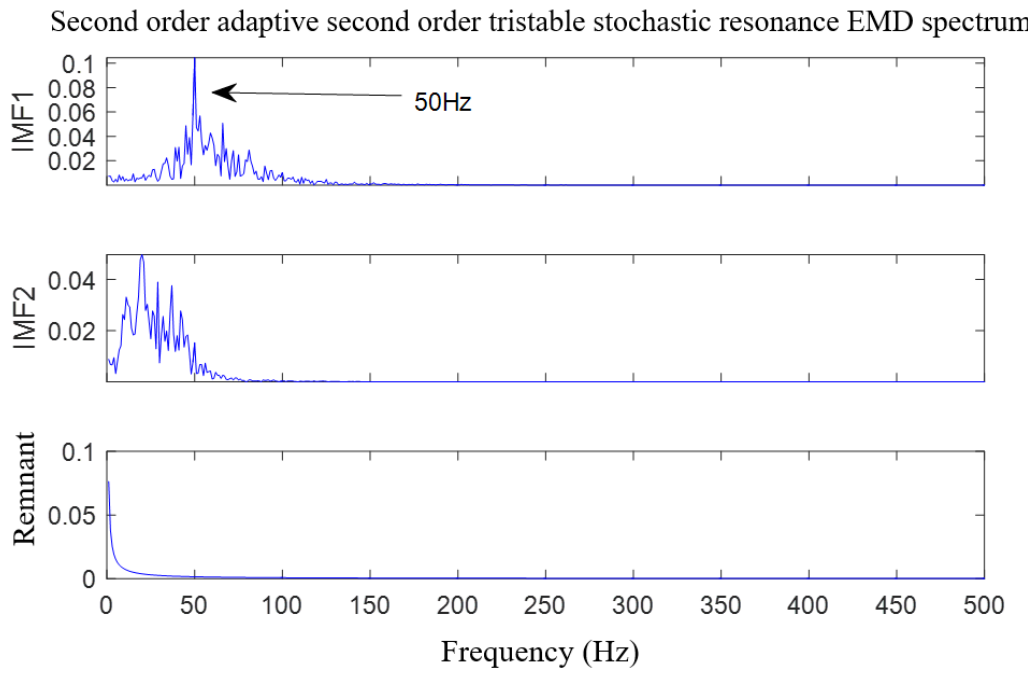

Figure 11. The processing results of the second-order stochastic resonance output.

From Figures 9-11, after the pretreatment of the noise signal by CASTSR is carried out, the high-frequency interference noise is transferred into the low frequency to increase the characteristic frequency. Compared with the result of direct EMD decomposition without noise reduction, the IMF component obtained by EMD is more accurate and clearer with fewer noise-interference components and more prominent characteristic frequency information. In addition, from the perspective of the IMF order of EMD decomposition, the IMF order of EMD decomposition decreases with the increase in CASTSR order, and the most direct result is the improvement in computing efficiency.

\section{Case Analysis}

The processing flow in Figure 3 is used to analyze the experimental signal in order to prove the effectiveness of the proposed method in practical engineering. The bearing fault data came from the Western Reserve University [62,63]. The experimental platform of the Western Reserve University is shown in Figure 12. Deep groove ball bearings 6205-2RS JEM SKF were used in the experiment; the bearing specific parameters were: inner ring 
diameter, $25.001 \mathrm{~mm}$; outer ring diameter, $51.999 \mathrm{~mm}$; pitch circle diameter, $39.4 \mathrm{~mm}$; roller diameter, $7.94 \mathrm{~mm}$; and the number of rollers, 9 .

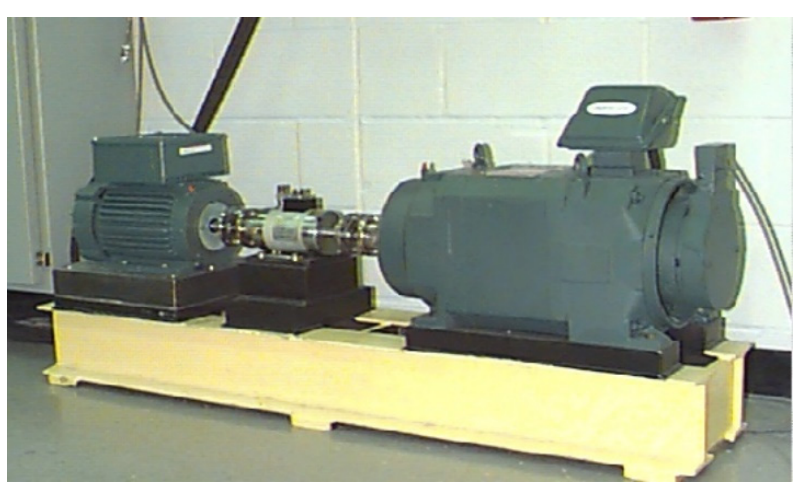

Figure 12. Rolling bearing experimental data test platform.

Bearing inner ring fault signals are collected from deep groove ball bearings with a motor speed of $1730 \mathrm{r} / \mathrm{min}$ and fault size of $0.011 \times 0.014$ (inch); the sampling frequency is $12 \mathrm{kHz}$, and the sampling points are 4096 . The theoretical value of the inner ring fault characteristic frequency $f_{i}=156.1 \mathrm{kHz}$ is obtained.

The power spectrum of inner ring fault signal is shown in Figure 13.
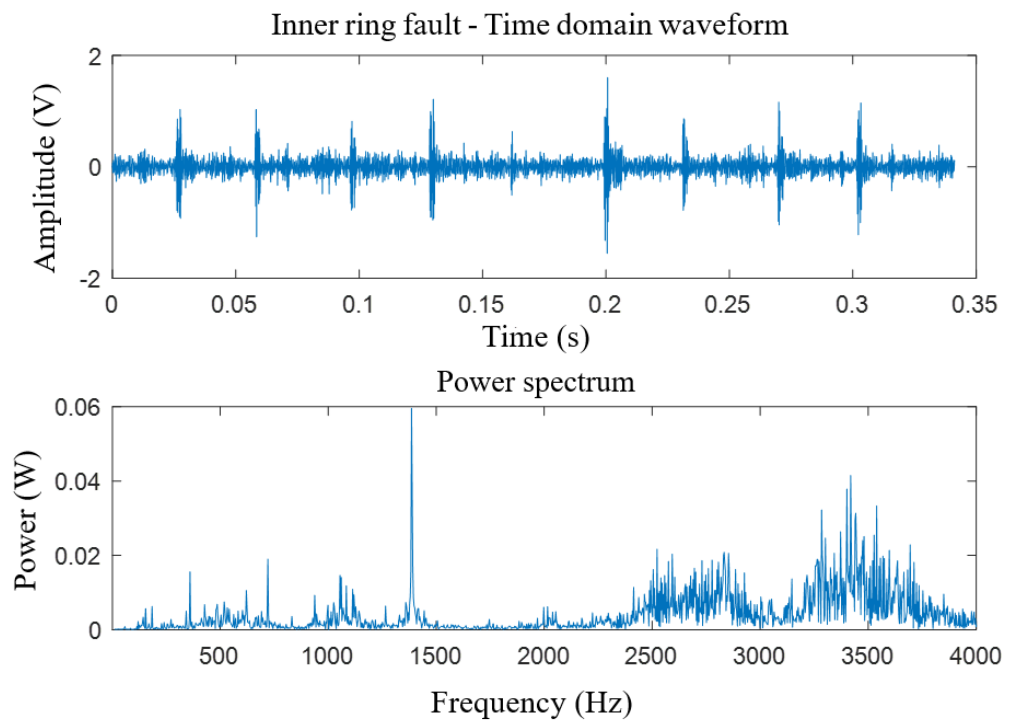

Figure 13. The power spectrum of inner ring fault signal.

It can be seen from Figure 13 that the fault characteristic frequency cannot be identified. The collected inner ring fault signal was applied to Hilbert transform, and the envelope spectrum was obtained as shown in Figure 14; its amplitude was $0.06528 \mathrm{~V}$. The characteristic frequency is in the surrounding noise and cannot be identified. The SNR is $-19.40 \mathrm{Db}$ by calculation.

The envelope spectrum signal after high-pass filtering is shown Figure 15, and most of the low-frequency interference components are filtered out.

The CASTSR method is used to analyze the inner ring fault signal. The output spectrum of the three-stage adaptive second-order tristable system is obtained in Figures 16-18. 


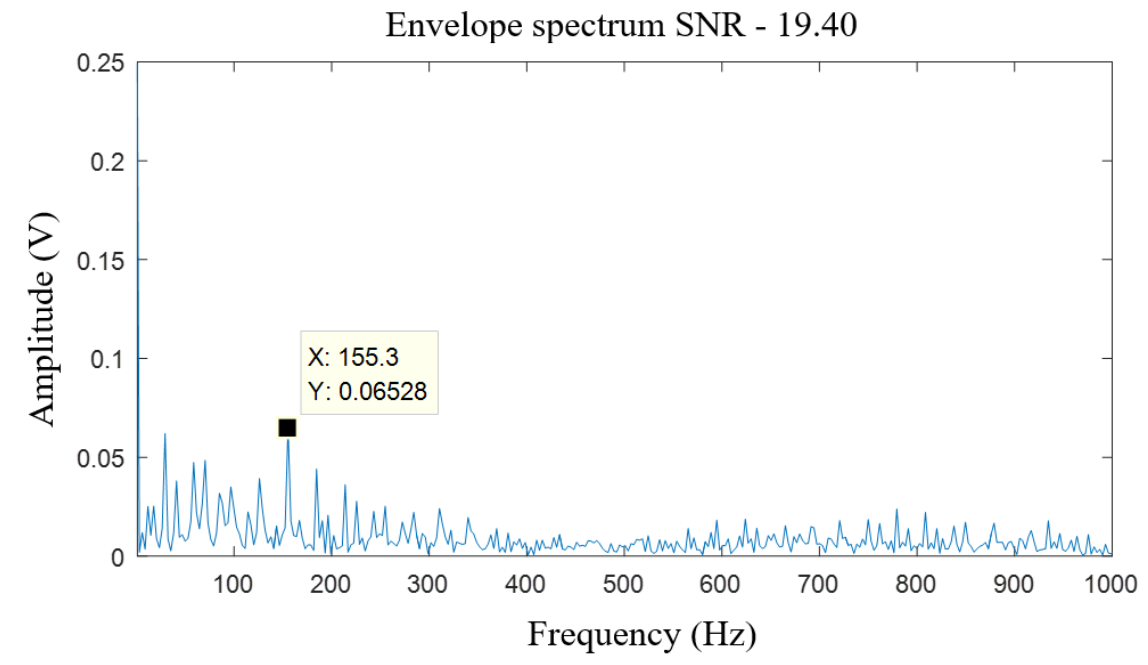

Figure 14. The envelope spectrum of original signal.

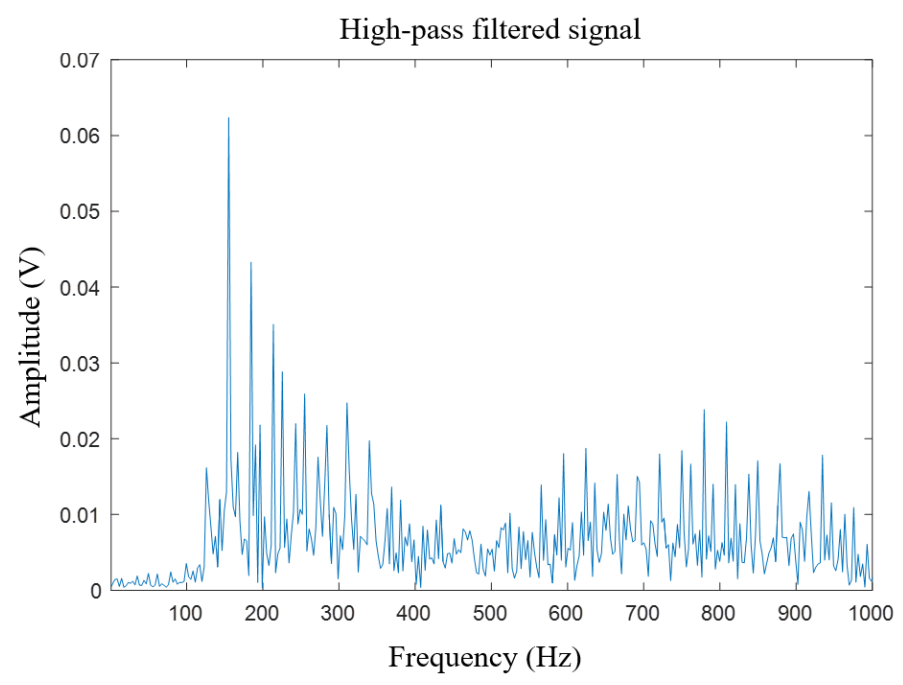

Figure 15. The envelope spectrum of high-pass filtered signal.

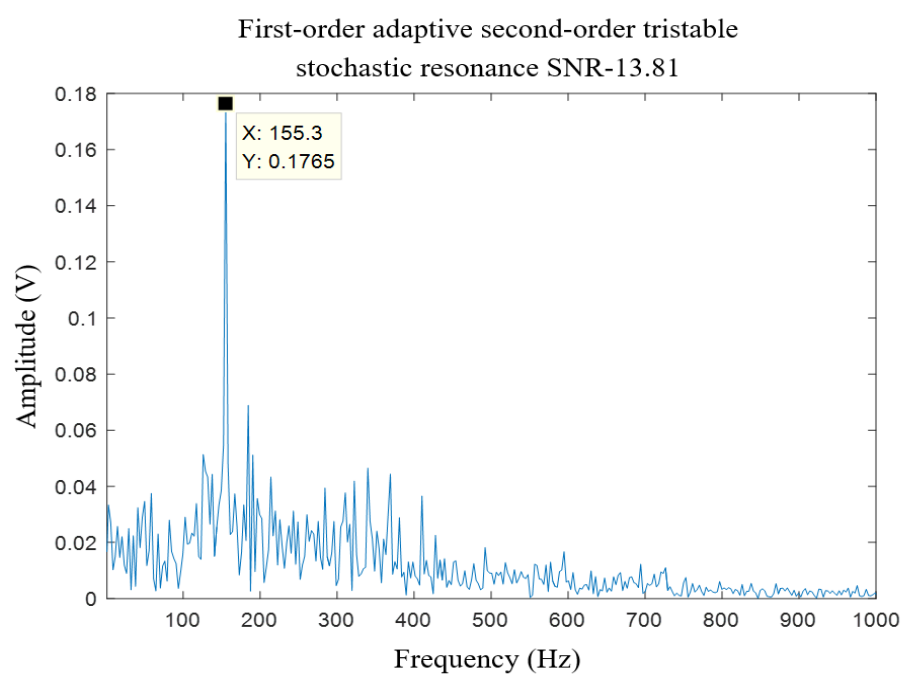

Figure 16. The output spectrum of the first cascade system. 


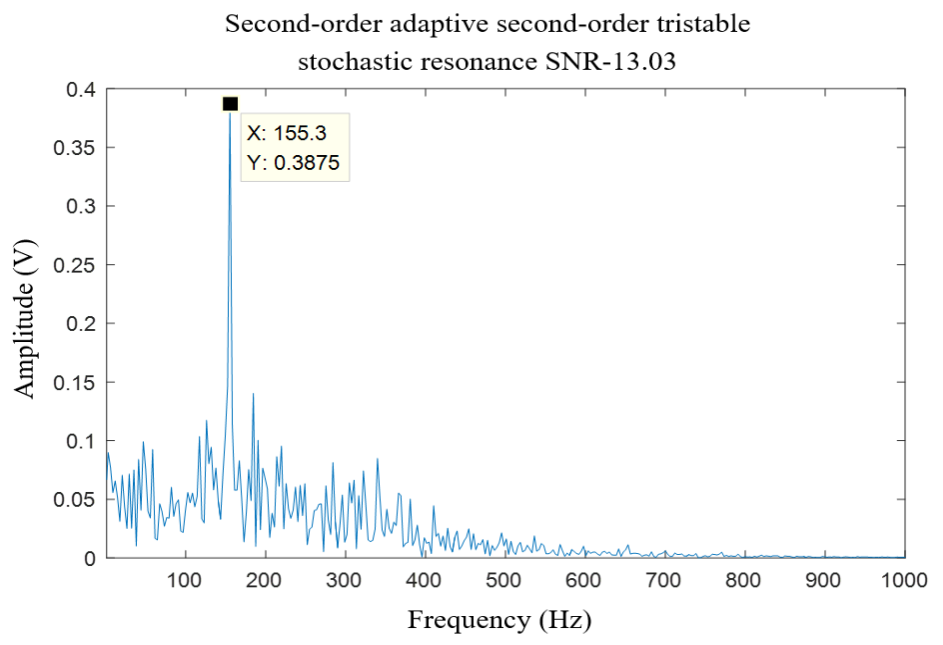

Figure 17. The output spectrum of the second cascade system.

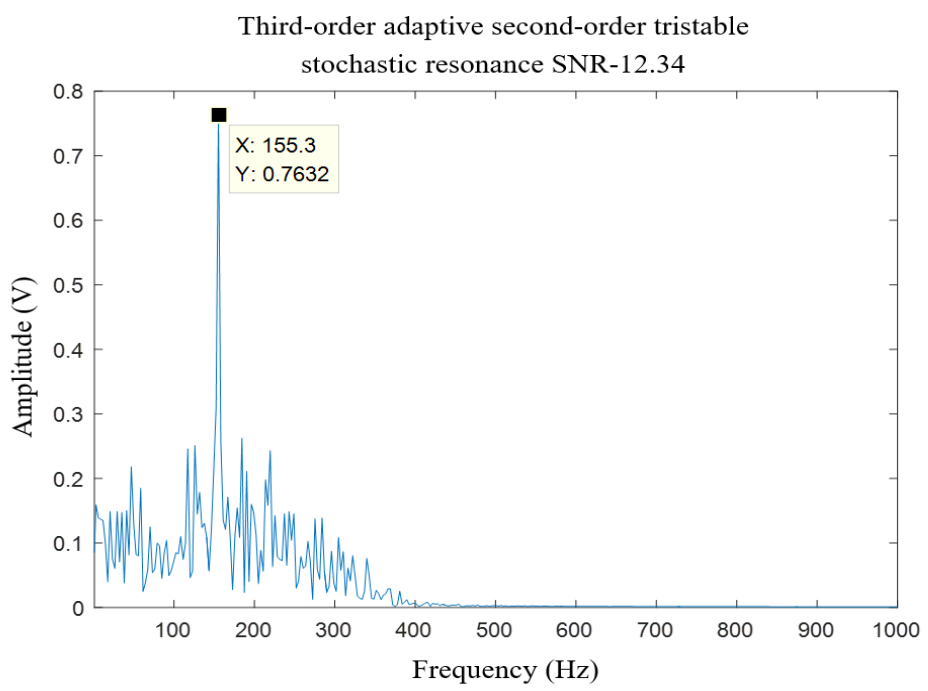

Figure 18. The output spectrum of the third cascade system.

As can be seen from the output spectra of Figures 16-18, the noise energy is continuously transferred from the high frequency to the low frequency by using the CSR system at the characteristic frequency of $155.3 \mathrm{~Hz}$. The peak value of the input signal, the first-order stochastic resonance results, the second-order stochastic resonance results and the third-order stochastic resonance results are all superior to the previous order stochastic resonance. In addition, from the perspective of the calculated output SNR, the first stage SNR reaches $-13.81 \mathrm{~dB}$, which is $5.59 \mathrm{~dB}$ higher than that of the inner ring fault envelope signal; the SNR of the second stage was $-13.03 \mathrm{~dB}$, which is $0.78 \mathrm{~dB}$ higher than that of the first stage; and the SNR of the third stage was $-12.34 \mathrm{~dB}$, which is $0.69 \mathrm{~dB}$ higher than that of the second stage. In general, the effect of stochastic resonance is significant, which verifies the effectiveness of the proposed CASTSR method to further extract weak signal features.

The results of the inner ring fault envelope signal directly decomposed by EMD are shown in in Figure 19. The first three orders are high-frequency noise. The feature frequencies are between IMF4 and IMF5, and the mode aliasing phenomenon occurs. Moreover, there are a lot of interference frequencies and noises around the feature frequencies, so the fault features cannot be accurately extracted. The processing results of noise reduction signals by using EMD are shown in Figures 20-22. 

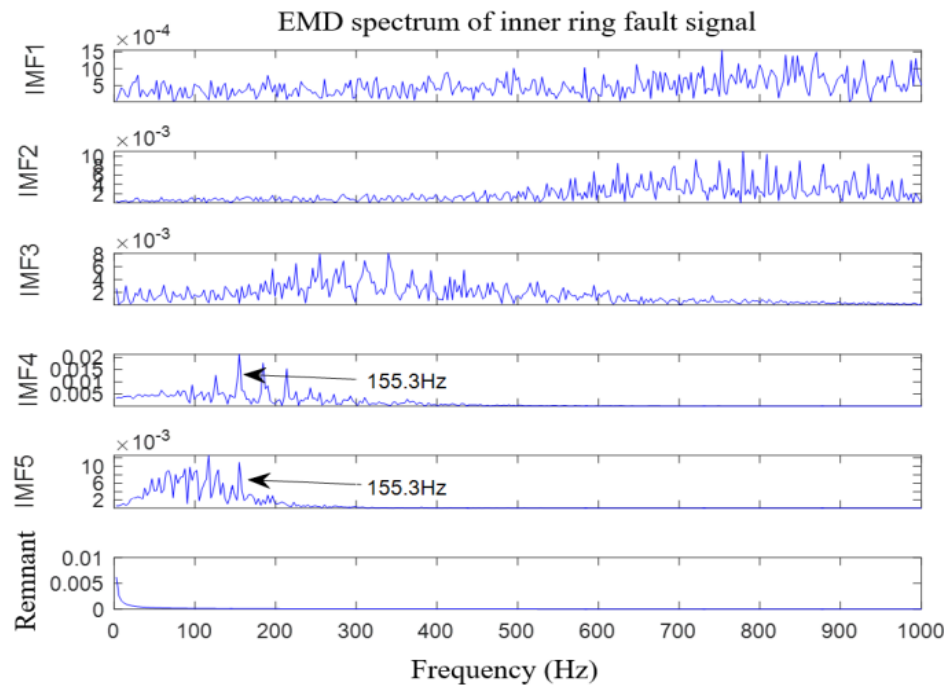

Figure 19. The processing results of inner ring fault signal.
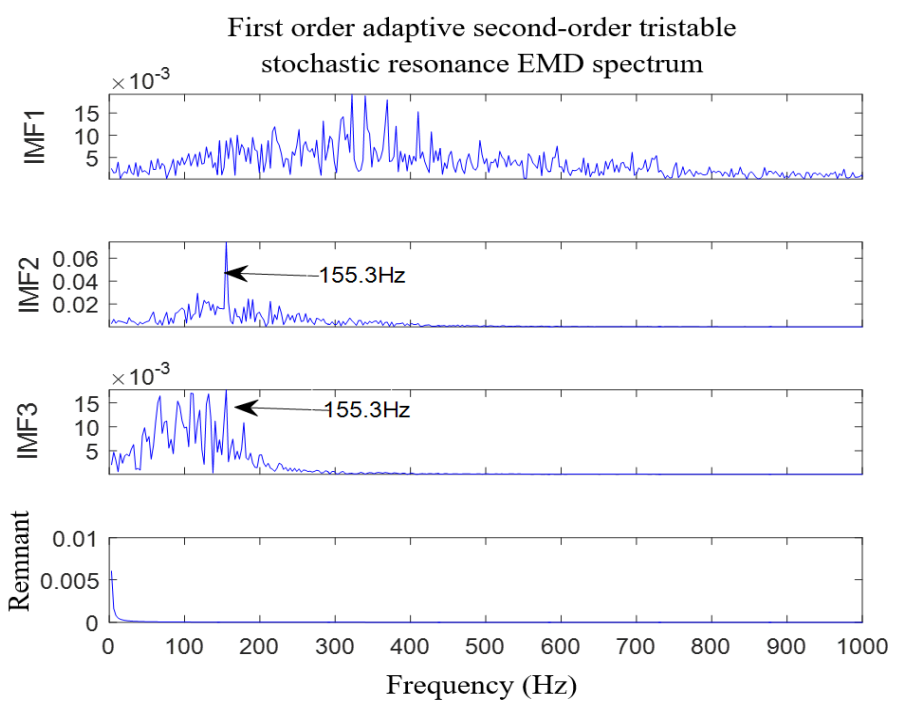

Figure 20. The processing results of the first cascaded stochastic resonance.
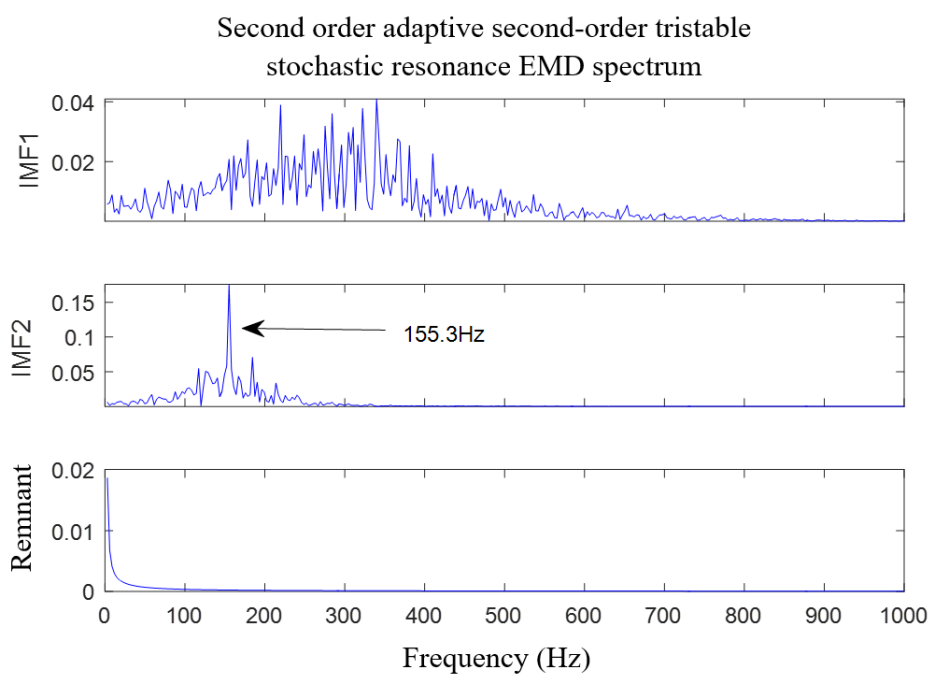

Figure 21. The processing results of the second cascaded stochastic resonance. 

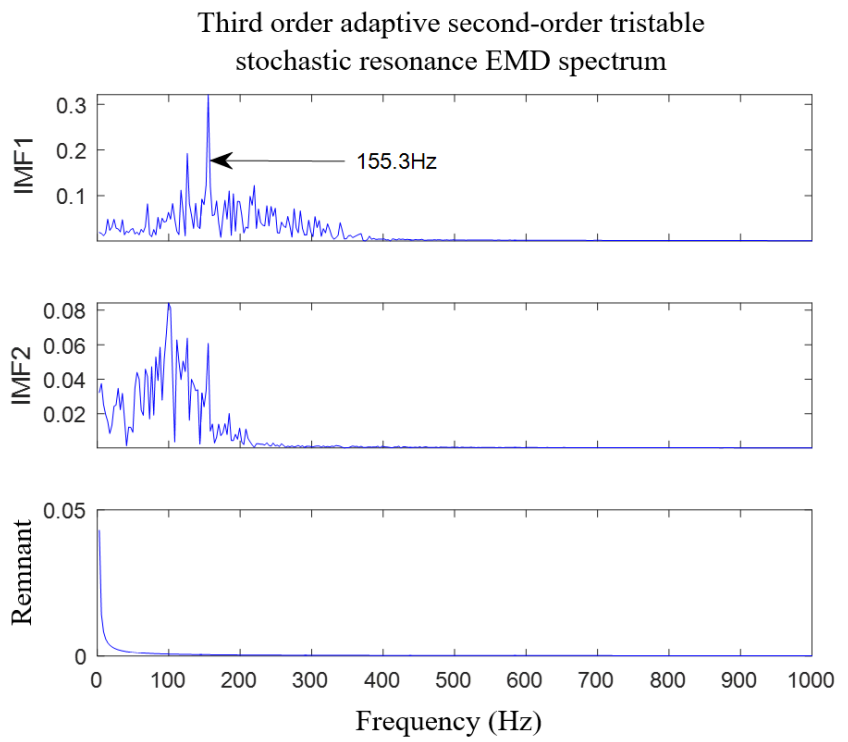

Figure 22. The processing results of the third cascaded stochastic resonance.

As can be seen from Figure 20, IMF1 is the high-frequency noise component; the characteristic frequencies appear in IMF2 and IMF3 with aliasing phenomena. In IMF2, the characteristic frequency is prominent, and there is no interference. However, there is a lot of interference noise around the characteristic frequency, and the characteristic frequency is weak in IMF3. Compared with the result of the inner ring fault envelope signal in Figure 19, the IMF order of EMD decomposition is reduced by two orders after the noise is reduced. As can be seen from Figure 21, the IMF1 is still high-frequency noise interference. In MF2, the characteristic frequency is prominent, there is no interference, and the mode aliasing phenomenon disappears. Compared with the first-order result in Figure 20, the IMF order of EMD decomposition decreases by one order after denoising is added. As can be seen from Figure 22, the characteristic frequency is in IMF1, and the characteristic frequency is very obvious and easy to identify, which indicates that the original signal has been fully denoised after the third-order stochastic resonance is carried out.

The experimental results show that the CASTSR method can reduce the IMF order of EMD decomposition and eliminate mode aliasing. After three intervals of stochastic resonance are carried out, the characteristic frequency is in the IMF1 by EMD decomposition, and the characteristic frequency becomes more prominent and obvious with the increase in the order, which improves the quality of SNR and EMD decomposition of the output signal. Therefore, CASTSR based on the EMD method can accurately extract the fault features of weak signals for the inner ring of rolling bearings.

\section{Conclusions}

Aiming at the problems of poor decomposition quality and poor extraction performance of weak signal features by using EMD under strong noise, the stochastic resonance theory and chaotic ACO are introduced to propose a new fault diagnosis method based on CASTSR and EMD. In the proposed method, chaotic ACO is used adaptively to adjust the parameters of the second-order tristable stochastic resonance system to obtain the best stochastic resonance. The measured signals were denoised and decomposed by using EMD. Finally, the characteristic frequencies were extracted from the IMF1. Simulation results and analysis results of bearing inner ring faults from Western Reserve University show that the proposed method can improve the quality of EMD decomposition, realize weak signal feature extraction, and improve the accuracy of fault diagnosis. 
Author Contributions: Conceptualization, H.C. and Y.G.; methodology, Y.G.; software, H.C.; validation, W.D.; data curation, Y.G.; writing-original draft preparation, H.C. and Y.G.; writing-review and editing, W.D.; project administration, funding acquisition, H.C. All authors have read and agreed to the published version of the manuscript.

Funding: This research was funded by the Science Researching Plans of Liaoning Province Education Department under Grant No. LJKZ0509.

Institutional Review Board Statement: Not applicable.

Informed Consent Statement: Not applicable.

Data Availability Statement: https:/ / csegroups.case.edu/bearingdatacenter/pages/welcome-casewestern-reserve-university-bearing-data-center-website (accessed on 28 June 2021).

Conflicts of Interest: The authors declare no conflict of interest.

\section{References}

1. Cui, H.J.; Guan, Y.; Deng, W. A novel advancing signal processing method based on coupled multi-stable stochastic resonance for fault detection. Appl. Sci. 2021, 11, 5385. [CrossRef]

2. Zhao, H.M.; Li, H.D.; Jin, Y.; Dang, X.J.; Deng, W. Feature extraction for data-driven remaining useful life prediction of rolling bearings. IEEE Trans. Instrum. Meas. 2021, 70, 3511910. [CrossRef]

3. Li, B.; Chow, M.Y.; Tipsuwan, Y.; Hung, J.C. Neural-network-based motor rolling bearing fault diagnosis. IEEE Trans. Ind. Electron. 2000, 47, 1060-1069. [CrossRef]

4. Zheng, J.; Yuan, Y.; Zou, L.; Deng, W.; Guo, C.; Zhao, H.M. Study on a novel fault diagnosis method based on VMD and BLM. Symmetry 2019, 11, 747. [CrossRef]

5. Guo, S.; Zhang, X.; Du, Y.; Zheng, Y.; Cao, Z. Path planning of coastal ships based on optimized DQN reward function. J. Mar. Sci. Eng. 2021, 9, 210. [CrossRef]

6. Li, W.; Li, Y.; Yu, L.; Ma, J.; Zhu, L.; Li, L.; Chen, H.; Deng, W. A novel fault feature extraction method for bearing rolling elements using optimized signal processing method. Appl. Sci. 2021, 11, 9095. [CrossRef]

7. Deng, W.; Shang, S.F.; Cai, X.; Zhao, H.M.; Xu, J.J. An improved differential evolution algorithm and its application in optimization problem. Soft Comput. 2021, 7, 5277-5298. [CrossRef]

8. Zhang, M.; Jiang, Z.N.; Feng, K. Research on variational mode decomposition in rolling bearings fault diagnosis of the multistage centrifugal pump. Mech. Syst. Signal Process. 2017, 93, 460-493. [CrossRef]

9. Hong, S.; Zhou, Z.; Enrico, Z.; Hong, K. Condition assessment for the performance degradation of bearing based on a combinatorial feature extraction method. Digit. Signal Process. 2014, 27, 159-166. [CrossRef]

10. Guo, Y.; Gou, K.; Sun, R.; Wei, J. Bearing fault diagnosis of injection machine based on empirical Mode decomposition. Plast. Sci. Technol. 2020, 48, 112-115.

11. Wang, Y. Research on fault diagnosis of electromechanical equipment based on multi-stable stochastic Resonance. Intern. Combust. Engine Parts 2021, 145-146.

12. Han, D.; Li, P.; An, S. Multi-frequency weak signal detection based on wavelet transform and parameter compensation band-pass multi-stable stochastic resonance. Mech. Syst. Signal Process. 2016, 70, 995-1010. [CrossRef]

13. Li, R.Y.; Sopon, P.; He, D. Fault features extraction for bearing prognostics. J. Intell. Manuf. 2021, 23, 313-321. [CrossRef]

14. Zhu, H.B.; He, Z.M.; Wei, J.H.; Wang, J.Q.; Zhou, H.Y. Bearing fault feature extraction and fault diagnosis method based on feature fusion. Sensors 2021, 21, 2524. [CrossRef]

15. Chen, Z.Q.; Guo, L.; Gao, H.L.; Yu, Y.X.; Wu, W.X.; You, Z.C.; Dong, X. A fault pulse extraction and feature enhancement method for bearing fault diagnosis. Measurement 2021, 182, 109718. [CrossRef]

16. Bao, W.; Zhou, R.; Yang, J.G.; Yu, D.R.; Li, N. Anti-aliasing lifting scheme for mechanical vibration fault feature extraction. Mech. Syst. Signal Process. 2009, 23, 1458-1473. [CrossRef]

17. Rai, V.K.; Mohanty, A.R. Bearing fault diagnosis using FFT of intrinsic mode functions in Hilbert-Huang transform. Mech. Syst. Signal Process. 2007, 21, 2607-2615. [CrossRef]

18. Wu, H.; Liang, S.; Zou, L. Method of evaluating aerodynamic damping of tall buildings based on wavelet analysis. J. Vib. Shock 2008, 4, 93-96.

19. Cheng, J.; Yang, Y.; Yang, Y. A rotating machinery fault diagnosis method based on local mean decomposition. Digit. Signal Process. 2012, 22, 356-366. [CrossRef]

20. Guo, W.; Peter, W.T. A novel signal compression method based on optimal ensemble empirical mode decomposition for bearing vibration signals. J. Sound Vib. 2013, 332, 423-441. [CrossRef]

21. Mandic, D.P.; Rehman, N.; Wu, Z.; Huang, N.E. Empirical mode decomposition-based time-frequency analysis of multivariate signals: The power of adaptive data analysis. IEEE Signal Process. Mag. 2013, 30, 74-86. [CrossRef]

22. Wu, Y.J.; Zhen, C.G.; Liu, C.L. Application of variational mode decomposition in wind power fault diagnosis. Mech. Transm 2015, 129-132. 
23. Pu, Z.X.; Yin, H.; Zhang, N.; Yan, W.; Peng, Z. Bearing fault diagnosis using vmd and stationary wavelet method based on kurtosis criterion. Mach. Des. Res. 2017, 33, 67-71.

24. Zhu, Y.L.; Jia, Y.F.; Wang, L.W.; Li, L.; Zheng, Y. Feature extraction and classification on partial discharge signals of power transformers based on improved variational mode decomposition and Hilbert transform. Trans. China Electrotech. Soc. 2017, 32, 221-235.

25. Miao, Y.; Zhao, M.; Lin, J. Identification of mechanical compound-fault based on the improved parameter-adaptive variational mode decomposition. ISA Trans. 2019, 84, 82-95. [CrossRef]

26. Jin, T.; Ding, H.; Xia, H.X.; Bao, J. Reliability index and Asian barrier option pricing formulas of the uncertain fractional first-hitting time model with Caputo type. Chaos Solitons Fractals 2021, 142, 110409. [CrossRef]

27. Chen, H.; Zhang, Q.; Luo, J.; Xu, Y.; Zhang, X. An enhanced bacterial foraging optimization and its application for training kernel extreme learning machine. Appl. Soft Comput. 2020, 86, 105884. [CrossRef]

28. Deng, W.; Shang, S.; Cai, X.; Zhao, H.; Zhou, Y.; Chen, H.; Deng, W.Q. Quantum differential evolution with cooperative coevolution framework and hybrid mutation strategy for large scale optimization. Knowl.-Based Syst. 2021, 224, 107080. [CrossRef]

29. Li, T.; Qian, Z.; Deng, W.; Zhang, D.Z.; Lu, H.; Wng, S. Forecasting crude oil prices based on variational mode decomposition and random sparse Bayesian learning. Appl. Soft Comput. 2021, 113, 108032. [CrossRef]

30. Wen, Z.C.; Zhang, Z.H.; Zhou, X.B.; Gu, J.G.; Shen, S.P.; Chen, G.S.; Deng, W. Tri-Partition Alphabet-Based State Prediction for Multivariate Time-Series. Appl. Sci. 2021, 11, 11294. [CrossRef]

31. Xu, Y.; Chen, H.; Luo, J.; Zhang, Q.; Jiao, S.; Zhang, X. Enhanced Moth-flame optimizer with mutation strategy for global optimization. Inf. Sci. 2019, 492, 181-203. [CrossRef]

32. Jin, T.; Xia, H.; Deng, W.; Li, Y.; Chen, H. Uncertain fractional-order multi-objective optimization based on reliability analysis and application to fractional-order circuit with Caputo type. Circuits Syst. Signal Process. 2021, 40, 5955-5982. [CrossRef]

33. Ang, K.M.; Lim, W.H.; Isa, N.; Tiang, S.S.; Wong, C.H. A constrained multi-swarm particle swarm optimization without velocity for constrained optimization problems. Expert Syst. Appl. 2020, 140, 112882. [CrossRef]

34. Deng, W.; Xu, J.; Gao, X.; Zhao, H. An enhanced MSIQDE algorithm with novel multiple strategies for global optimization problems. IEEE Trans. Syst. Man Cybern. Syst. 2020, 99, 1-10. [CrossRef]

35. Xu, Y.; Chen, H.; Heidari, A.A.; Luo, J.; Zhang, Q.; Zhao, X.; Li, C. An efficient chaotic mutative moth-flame-inspired optimizer for global optimization tasks. Expert Syst. Appl. 2019, 129, 135-155. [CrossRef]

36. Zhong, K.; Zhou, G.; Deng, W.; Zhou, Y.; Luo, Q. MOMPA: Multi-objective marine predator algorithm. Comput. Methods Appl. Mech. Eng. 2021, 385, 114029. [CrossRef]

37. Li, T.Y.; Shi, J.Y.; Zhang, D.Z. Color image encryption based on joint permutation and diffusion. J. Electron. Imaging 2021, 30, 013008. [CrossRef]

38. Jin, T.; Ding, H.; Li, B.; Xia, H.; Xue, C. Valuation of interest rate ceiling and floor based on the uncertain fractional differential equation in Caputo sense. J. Intell. Fuzzy Syst. 2021, 40, 5197-5206. [CrossRef]

39. Li, Y.; Li, X.; Gao, L.; Meng, L. An improved artificial bee colony algorithm for distributed heterogeneous hybrid flowshop scheduling problem with sequence-dependent setup times. Comput. Ind. Eng. 2020, 147, 106638. [CrossRef]

40. Jin, T.; Xia, H.X. Lookback option pricing models based on the uncertain fractional-order differential equation with Caputo type. J. Ambient. Intell. Humaniz. Comput. 2021, 1-14. [CrossRef]

41. Yang, X.; Liu, J.; Liu, Y.; Xu, P.; Yu, L.; Zhu, L.; Chen, H.; Deng, W. A novel adaptive sparrow search algorithm based on chaotic mapping and t-distribution mutation. Appl. Sci. 2021, 11, 11192. [CrossRef]

42. Ma, A.X.; Zhang, X.H.; Zhang, C.S.; Zhang, B.; Gao, Y. An adaptive ant colony algorithm for dynamic traveling salesman problem. J. Inf. Sci. Eng. 2019, 35, 1263-1277.

43. Luo, J.; Chen, H.; Heidari, A.A.; Xu, Y.; Zhang, Q.; Li, C. Multi-strategy boosted mutative whale-inspired optimization approaches. Appl. Math. Model. 2019, 73, 109-123. [CrossRef]

44. Tu, J.; Chen, H.; Liu, J.; Heidari, A.A.; Pham, Q.V. Evolutionary biogeography-based whale optimization methods with communication structure: Towards measuring the balance. Knowl.-Based Syst. 2021, 212, 106642. [CrossRef]

45. Deng, W.; Xu, J.; Song, Y.; Zhao, H. An effective improved co-evolution ant colony optimisation algorithm with multi-strategies and its application. Int. J. Bio-Inspired Comput. 2020, 16, 158-170. [CrossRef]

46. Zhang, Z.H.; Min, F.; Chen, G.S.; Shen, S.; Wen, Z.; Zhou, X. Tri-partition state alphabet-based sequential pattern for multivariate time series. Cogn. Comput. 2021. [CrossRef]

47. Ran, X.; Zhou, X.; Lei, M.; Tepsan, W.; Deng, W. A novel k-means clustering algorithm with a noise algorithm for capturing urban hotspots. Appl. Sci. 2021, 11, 11202. [CrossRef]

48. Cui, H.; Guan, Y.; Chen, H. Rolling element fault diagnosis based on VMD and sensitivity MCKD. IEEE Access 2021, 9, 120297120308. [CrossRef]

49. Deng, W.; Zhang, X.; Zhou, Y.; Liu, Y.; Zhou, X.; Chen, H.; Zhao, H. An enhanced fast non-dominated solution sorting genetic algorithm for multi-objective problems. Inform. Sci. 2021. [CrossRef]

50. Xing, Z.; Yi, C.; Lin, J.; Zhou, Q. Multi-component fault diagnosis of wheelset-bearing using shift-invariant impulsive dictionary matching pursuit and sparrow search algorithm. Measurement 2021, 178, 109375. [CrossRef]

51. Deng, W.; Xu, J.; Zhao, H.; Song, Y. A novel gate resource allocation method using improved PSO-based QEA. IEEE Tran. Intell. Transp. Syst. 2020, 1-9. [CrossRef] 
52. Yong, W.; Wong, K.; Liao, X.; Chen, G. A new chaos based fast image encryption algorithm. Appl. Soft Comput. 2011, 11, 514-522.

53. Zhao, H.M.; Liu, H.L.; Xu, J.J.; Guo, C.; Deng, W. Research on a fault diagnosis method of rolling bearings using variation mode decomposition and deep belief network. J. Mech. Sci. Technol. 2020, 33, 4165-4172. [CrossRef]

54. Li, J.M.; Zhang, J.F.; Li, M.; Zhang, Y. A novel adaptive stochastic resonance method based on coupled bistable systems and its application in rolling bearing fault diagnosis. Mech. Syst. Signal Process. 2019, 114, 128-145. [CrossRef]

55. Wei, Y.; Zhou, Y.; Luo, Q.; Deng, W. Optimal reactive power dispatch using an improved slime mould algorithm. Energy Rep. 2021, 7, 8742-8759. [CrossRef]

56. Li, S.; Chen, H.; Wang, M.; Heidari, A.A.; Mirjalili, S. Slime Mould algorithm: A new method for stochastic optimization. Future Gener. Comput. Syst. 2020, 111, 300-323. [CrossRef]

57. Du, Y.; Wang, Z.M.; Li, M.H. Intrusion detection method of industrial control based on optimized nuclear extreme learning machine. Inf. Netw. Secur. 2021, 21, 1-9.

58. Zhao, H.; Li, D.; Deng, W.; Yang, X. Research on vibration suppression method of alternating current motor based on fractional order control strategy. Proc. Inst. Mech. Eng. E J. Process 2017, 231, 786-799. [CrossRef]

59. Li, X.; Yang, Y.; Shao, H.D.; Zhong, X.; Cheng, J. Symplectic weighted sparse support matrix machine for gear fault diagnosis. Measurement 2021, 168, 108392. [CrossRef]

60. Zhao, H.M.; Sun, M.; Deng, W.; Yang, X. A new feature extraction method based on EEMD and multi-scale fuzzy entropy for motor bearing. Entropy 2016, 19, 14. [CrossRef]

61. Shao, H.D.; Lin, J.; Zhang, L.W.; Galar, D.; Kumar, U. A novel approach of multisensory fusion to collaborative fault diagnosis in maintenance. Inf. Fusion 2021, 74, 65-76. [CrossRef]

62. Rilling, G.; Flandrin, P.; Lilly, J.M. Bivariate empirical mode decomposition. IEEE Signal Process. Lett. 2007, 14, 936-939. [CrossRef]

63. Available online: https://csegroups.case.edu/bearingdatacenter/pages/welcome-case-western-reserve-university-bearingdata-center-website (accessed on 28 June 2021). 